\title{
The Effect of two Surgical Approach Lordosis Correction in Degenerative Lumbar Diseases: Minimally Invasive Oblique Lumbar Interbody Fusion (OLIF) Versus Transforminal Lumbar Interbody Fusion (TLIF)
}

\author{
Renjie Li, Xiaofeng Shao* and Weimin Jiang \\ Department of Orthopaedics, First Affiliated Hospital of Soochow University, China
}

*Corresponding author: Weimin Jiang, Department of Orthopaedics, First Affiliated Hospital of Soochow University, Shizi Street, Suzhou, Jiangsu Province, China

\begin{abstract}
Background: The present study aimed to compare clinical outcomes and radiographic results of oblique lumbar interbody fusion (OLIF) with transforaminal lumbar interbody fusion (TLIF) in patients with lumbar spondylolisthesis.

Methods: We retrospectively reviewed and compared 28 patients who underwent OLIF (OLIF group) and 35 who underwent TLIF (TLIF group). The operation time, intraoperative hemorrhage, bed rest duration, and length of hospital stay were compared between the 2 groups. Clinical results were evaluated with the ODI and VAS for back and leg pain. Radiological results were evaluated with disc height (DH), foraminal height (FH), fused segment lordosis (FSL) and lumbar lordosis (LL).

Results: The OLIF group had less intraoperative blood loss, shorter operative time, bed rest time, and hospital stay than TLIF group $(\mathrm{P}<0.05)$. The OLIF group had lower VAS scores for back pain and lower VAS scores for leg pain after surgery compared with before surgery $(\mathrm{P}<0.05)$, The OLIF group had lower ODI after surgery compared with before surgery $(\mathrm{P}<0.05)$.The was no significant difference in decrease value in VAS and ODI after surgery between the two groups $(\mathrm{P}>0.05)$. No significant differences were found in $\mathrm{DH}, \mathrm{FH}$ and LL between the 2 groups preoperatively $(\mathrm{P}>0.05)$. The OLIF group showed higher DH and FH than the TLIF group at all time points $(\mathrm{P}<0.05)$. No significant differences were found in FSH between the 2 groups at any time point.
\end{abstract}

Conclusions: OLIF has similar good long-term clinical outcomes of TLIF with the additional benefits of less initial postoperative pain, early rehabilitation, shorter hospitalization, and fewer complications.

Keywords: Lumbar Spondylolisthesis; Oblique Lumbar Interbody Fusion; Transforaminal Lumbar Interbody Fusion; Sagittal Balance

\section{Introduction}

Lumbar spondylolisthesis describes a forward displacement of a lumbar vertebra. The most common types are degenerative or isthmic lumbar spondylolisthesis. It is a common pathology, often causing lumbar canal stenosis. Symptoms of lumbar spondylolisthesis may include intermittent neurogenic claudication, lumbar radiculopathy and back pain [1]. The primary treatment for lumbar spondylolisthesis is non-surgical. When unsuccessful, surgery can be considered in order to decompress neural structures and stabilize the spine. Lumbar fusion has become an accepted treatment to treat degenerative diseases of the lumbar spine. There is a growing body of evidence that consistently demonstrates improved clinical outcomes with lumbar fusions for patients who fail conservative care [2]. Transforaminal lumbar interbody fusion (TLIF) is one of the widely used techniques for spinal fusion. The first attempt for TLIF was by Harms and Rolinger, who reported on the use of bone graft packed in titanium mesh that was inserted via a unilateral transforaminal route into the anterior part of the disc space. Harms and Blumes developed the TLIF technique further, and Harms described this in detail together with Jeszensky in 1998 [3-5] It is a posterior approach that uses a facetectomy corridor and has benefits of safety, good outcomes, and high fusion rate. Surgeons prefer this approach because they can reduce dural 
retraction and enable direct neural decompression. However, characteristic complications include posterior spinal muscle injury and cerebrospinal fluid (CSF) leakage $[6,7]$. The OLIF was first described by Mayer et al in 1997, and the term was later coined by Silvestre et al in 2012. This approach aims to avoid the morbidity of the transpsoas approach by translating the incision anteriorly and dissecting around the psoas [8,9] Oblique lateral interbody fusion (OLIF) is a new technique in spine surgery, through oblique lateral retroperitoneal approach, it can establish a work corridor direct access to the intervertebral space between the psoas muscles and the abdominal vessels sheath. Through the retroperitoneal work corridor, OLIF can complete intervertebral fusion of anterior and middle column, restore the height of intervertebral space and foramen, and make the spinal canal or nerve root indirect decompression. OLIF is applicable to degenerative lumbar spine diseases, spinal tuberculosis, tumor, kyphosis, postoperative renovation and trauma, etc. OLIF conforms to the current trend of minimally invasive spinal surgery, which has many advantages like less surgical trauma, less surgical bleeding loss, shorter hospital stay, faster recovery, less damage to the abdominal organs, no stimulation of the spinal nerve and less damage to the psoas and lumbosacral plexus [10-12]. The aim of this study was to compare OLIF and TLIF for the treatment of lumbar spondylolisthesis in terms of clinical outcomes and radiographic results.

\section{Methods}

\section{Patients}

The study enrolled patients who underwent TLIF (TLIF group) or OLIF (OLIF group) in our department between January 2018 and October 2019. The surgery apporach was deteminated by the patien's desirement. The inclusion criteria were as follows: all patients were operated for a single lumbar level and they had complaints of low back pain and lower limb pain unresponsive to conservative therapy for over 3 months, radicular symptom and/ or intermittent claudication before the operation. Preoperative examination included a detailed physical examination and radiological imaging. Patients with previous spinal instrumentation, spinal tumor pathologies, spinal infections, and acute spinal trauma or fractures were excluded. Among them, 28 patients underwent OLIF (OLIF group) and 35 patients underwent TLIF (TLIF group) The health records and radiographic data of the 64 patients were summarized and analyzed. This study was reviewed and approved by the Ethics Committee of the First Affiliated Hospital of Soochow University.

\section{Operative Procedure}

\section{Oblique lumbar interbody fusion}

After induction of general anesthesia, the patient was placed in lateral decubitus position on the right side. The operating segment was marked on the skin via a C-arm machine. A $5 \mathrm{~cm}$ skin incision was made on the marked disc level at the left abdomen. Then carry out blunt finger dissection of the abdominal oblique muscles, which includes the external oblique, internal oblique, and transversalis abdominis muscles. The surgeon uses the index finger to confirm the anterior border of the psoas muscle, sliding from the quadratus lumborum muscle to reach there. The retroperitoneal space was accessed by blunt dissection, and the peritoneal content was mobilized anteriorly. Place a Kirschner wire into the disc space from the antero-laterl corner to confirm the target disc space again. Sequential dilators were placed over the Kirschner wire. After the final tubular retractor was placed over the anterior onethird of the disk under illumination, the entire visualized area was made clearly. A lateral annulotomy was performed followed by a complete discectomy by using pituitary rongeurs and curettes, then removing the focus by using curette. After that, an appropriate-sized cage filled with autologous bone graft was inserted orthogonally in a press-fit fashion into the disc spaces. The above procedures were done step by step under C-arm fluoroscopic guidance. After completing the anterior procedure, the patient was turned to the prone position, and supplemental posterior instrumentation was then placed with a midline incision to sustain the stability of spine.

\section{Transforaminal lumbar interbody fusion}

After induction of general anesthesia, the patient was placed in a prone position on a carbon table. Then mark the target level under the $\mathrm{C}$-arm guidance. A midline incision was made. The skin and subcutaneous tissue were incised layer by layer and the paravertebral muscles were dissected from the spine. Pedicle screw-rod was inserted bilaterally. The facet joint and part of the vertebral lamina were removed by osteotome and the disk was then removed. After resection of ligamentum flavum and osteophyte, a cage filled with autologous bone was inserted in the disc space. The wound was copiously irrigated and closed in layers.

\section{Assessment of Clinical and Radiographic Outcomes}

The duration of the operation, volume of intraoperative hemorrhage, length of bed rest, length of hospital stay and complications were recorded for all patients. Clinical and radiographic outcomes were evaluated preoperatively and at 1 week, 3 months and 6 months postoperatively. We used the visual analog scale (VAS) for leg pain (VAS-LP) and back pain (VAS-BP) and the Oswestry Disability Index (ODI) to compare clinical outcomes between the two groups. Lumbar lordosis (LL), disc height (DH), foraminal height (FH), LL was defined as the angle between the upper endplate of the L1 and S1 vertebra using the Cobb method. DH was calculated as the mean value of the anterior and posterior margin heights of the affected disc. FH was measured as the maximal interval between the lower border of the upper pedicle and the upper border of the lower pedicle. Two observations were made at an interval of at least 2 weeks by two neurosurgeons, and the mean values were used for the study.

\section{Statistical Analysis}

The data analysis were performed by Statistical Package for the Social Sciences (version 19.0 SPSS, Chicage, IL) and Microsfot Excel 2016 (Microsoft, Seattle, WA). All quantitative variables are presented as means \pm standard deviations. Student's t-test and the chisquared test were used to compare radiological and clinical outcomes of OLIF and TLIF. The difference between the two groups 
were assessed by using Chi-square test. $\mathrm{P}<.05$ was considered statistically significant.

\section{Results}

No significant differences were found between the 2 groups in terms of baseline patient characteristics, including age, sex, body mass index and operated levels (Table1). The operative duration was shorter and intraoperative hemorrhage was less in the OLIF group compared with the TLIF group $(186.44 \pm 36.5$ vs. $199 \pm 59.64 \mathrm{~min}$; $55.94 \pm 57.37$ vs. $190 \pm 66.33 \mathrm{~mL}$; respectively). The OLIF group had a shorter bed rest time and shorter hospital stay than did the TLIF group $(\mathrm{P}<0.05)$ (Table1). VAS scores of both groups decreased postoperatively (Table2). No significant differences in VAS (BP) scores were found at preoperative and postoperative 3 months between the 2 groups $(\mathrm{P}>0.05)$. Statistical difference was found at 1 week after surgery $(\mathrm{P}<0.05)$. No significant differences in VAS (LP) scores were found at any follow up time. Preoperative ODI were 54.88 \pm 8.13 and $53.93 \pm 6.06$ points in the OLIF and TLIF groups, respectively ( $\mathrm{P}>0.05)$, which both decreased postoperatively. No significant differences in ODI scores were found at preoperative and postoperative 3 months between the 2 groups $(\mathrm{P}>0.05)$. Statistical difference was found at 1 week after surgery $(\mathrm{P}<0.05)$. No significant differences in $\mathrm{DH}$ and $\mathrm{FH}$ between the 2 groups were seen preoperatively $(\mathrm{P}>0.05)$. The postoperative $\mathrm{FH}$ and $\mathrm{DH}$ was significantly greater than the preoperative value in each group $(\mathrm{p}<0.01)$. The postoperative $\mathrm{DH}$ was significantly greater in the OLIF group than in the TLIF group $(\mathrm{p}<0.01)$. The postoperative $\mathrm{FH}$ and $\mathrm{DH}$ was significantly greater than the preoperative value in each group $(\mathrm{p}<0.05)$. The OLIF showed higher DH and FH than the TLIF group at all time points after surgery $(p<0.05)$. There was no statistically difference found in LL between the two groups before surgery ( $>>0.05$ ), but the recovery of LL in OLIF group was significantly greater than that in TLIF group $(\mathrm{P}<0.05)$. Both groups showed increased FSL after surgery, while no significant differences in FSL were found between the 2 groups at any follow-up time point (Table 3). For patients in TLIF group with a combination of supplemental fixation at a given level, there was $8.6 \%$ ( 3 of 35 ) rate of cage subsidence. Of the 3 patients with radiographical subsidence, only 1 was symptomatic. Besides, for patients in OLIF group with a combination of unilateral fixation, there was $7.1 \%$ ( 2 of 28 ) of cage sedimentation. In OLIF group, two patients showed ileus on the first postoperative day which improved spontaneously the next several days. One patient experienced thigh and numbness postoperatively, which alleviated within 7 days after surgery. There was no ureteral injury or lesion to sympathetic chain. In the TLIF group, CSF leakage due to thecal sac injury and root injury was confirmed in three cases. The drainage tube was removed 7 days after the operation. Superficial incision infection occurred in 3 patients in the TLIF group, which was treated with dressing change and antibiotics.

Table 1: Preoperative patient data and operative details in the two groups undergoing different surgical approach.

\begin{tabular}{|c|c|c|c|}
\hline Demographic & OLIF & TLIF & $\mathbf{P}$ \\
\hline cases & 28 & 35 & - \\
\hline Age(years) & $57.5 \pm 10.4$ & $59.3 \pm 9.86$ & .64 \\
\hline Sex(male/female) & $7 / 21$ & $8 / 27$ & .44 \\
\hline Blood loss (ml) & $55.94 \pm 57.37$ & $190 \pm 66.33$ & $2.53 \times 10-6$ \\
\hline Operative time(min) & $186.44 \pm 36.5$ & $199 \pm 59.64$ & .496 \\
\hline Bed rest time (d) & $2.81 \pm 1.24$ & $3.67 \pm 0.79$ & .036 \\
\hline $\operatorname{LOS}(d)$ & $7.06 \pm 2.51$ & $12.87 \pm 2.60$ & $1.18 \times 10-6$ \\
\hline BMI $(\mathrm{kg} / \mathrm{m} 2)$ & $25.29 \pm 3.15$ & $23.66 \pm 2.38$ & .128 \\
\hline Smoking & 5 & 4 & .469 \\
\hline $\mathrm{CCD}(\mathrm{n})$ & 0 & 0 & - \\
\hline Diabetes mellitus(n) & 2 & 6 & .236 \\
\hline $\operatorname{COPD}(\mathrm{n})$ & 1 & 0 & .260 \\
\hline CCI & $2.3125 \pm 0.68$ & $3.07 \pm 1.18$ & .043 \\
\hline Slipped segment & $\begin{array}{c}\text { L3 }(n=3) \\
\text { L4 (n=25) }\end{array}$ & $\begin{array}{c}\text { L3 (n=1) } \\
\text { L4 }(n=29) \\
\text { L5(n=5) }\end{array}$ & - \\
\hline Spondylolis thesis grade & $\begin{array}{l}\mathrm{I}^{\circ}(\mathrm{n}=12) \\
\mathrm{II}^{\circ}(\mathrm{n}=16)\end{array}$ & $\begin{array}{c}\mathrm{I}^{\circ}(\mathrm{n}=19) \\
\mathrm{II}^{\circ}(\mathrm{n}=16)\end{array}$ & - \\
\hline
\end{tabular}

Table 2: The outcomes of clinical parameters measured before and during follow-up.

\begin{tabular}{|c|c|c|c|}
\hline & OLIF & TLIF & P \\
\hline VAS(back pain) & $7.19 \pm 1.56$ & $7.33 \pm 1.54$ & 0.795 \\
Pre-op & $2.81 \pm 1.52$ & $3.87 \pm 1.60$ & 0.004 \\
Post-op 1 w & $0.44 \pm 0.51$ & $0.47 \pm 0.52$ & 0.875 \\
Post-op 3 m & & \\
\hline
\end{tabular}




\begin{tabular}{|c|c|c|c|}
\hline VAS(leg pain) & $6.5 \pm 0.97$ & $6.67 \pm 1.29$ & 0.686 \\
Pre-op & $2.88 \pm 0.81$ & $2.93 \pm 0.80$ & 0.841 \\
Post-op 1 w & $0.38 \pm 0.48$ & $0.60 \pm 0.49$ & 0.224 \\
Post-op 3 m & $54.88 \pm 8.13$ & $53.93 \pm 6.06$ & 0.719 \\
\hline ODI, \% & $22.44 \pm 2.61$ & $28.13 \pm 2.07$ & $2.30 \times 10-6$ \\
Pre-op & $17.06 \pm 1.29$ & $18.00 \pm 1.77$ & 0.101 \\
Post-op 1 w & & & \\
\hline
\end{tabular}

Table 3: The outcomes of radiological parameters measured before and during follow-up.

\begin{tabular}{|c|c|c|c|}
\hline Parameters & OLIF & TLIF & $\mathbf{p}$ \\
\hline $\begin{array}{c}\text { SP } \% \\
\text { Pre-op } \\
\text { Post-op 1 w } \\
\text { Post-op } 3 \mathrm{~m} \\
\text { Post-op } 6 \mathrm{~m} \\
\end{array}$ & $\begin{array}{c}26 \pm 5.25 \\
14.03 \pm 4.47 \\
14.43 \pm 4.11 \\
14.49 \pm 4.13\end{array}$ & $\begin{array}{c}26.47 \pm 6.08 \\
16.2 \pm 4.79 \\
17.13 \pm 4.05 \\
17.2 \pm 4.02\end{array}$ & $\begin{array}{l}.826 \\
.217 \\
.063 \\
.064 \\
\end{array}$ \\
\hline $\begin{array}{c}\text { LL }^{\circ} \\
\text { Pre-op } \\
\text { Post-op } 1 \mathrm{w} \\
\text { Post-op } 3 \mathrm{~m} \\
\text { Post-op } 6 \mathrm{~m}\end{array}$ & $\begin{array}{c}31.93 \pm 14.47 \\
44.47 \pm 13.10 \\
43.0 \pm 13.44 \\
42.4 \pm 13.26\end{array}$ & $\begin{array}{c}31.13 \pm 10.74 \\
35.07 \pm 7.47 \\
34.47 \pm 7.09 \\
34.07 \pm 7.14\end{array}$ & $\begin{array}{l}.869 \\
.028 \\
.046 \\
.049\end{array}$ \\
\hline $\begin{array}{c}\text { FSL }^{\circ} \\
\text { Pre-op } \\
\text { Post-op } 1 \mathrm{w} \\
\text { Post-op } 3 \mathrm{~m} \\
\text { Post-op } 6 \mathrm{~m}\end{array}$ & $\begin{array}{c}8.06 \pm 4.99 \\
13.31 \pm 5.54 \\
12.56 \pm 5.26 \\
12.38 \pm 4.99\end{array}$ & $\begin{array}{c}12.47 \pm 8.6 \\
17.47 \pm 8.94 \\
16.74 \pm 8.48 \\
16.53 \pm 8.20\end{array}$ & $\begin{array}{l}.099 \\
.141 \\
.119 \\
.108\end{array}$ \\
\hline $\begin{array}{c}\text { DH } \\
\text { Pre-op } \\
\text { Post-op } 1 \mathrm{w} \\
\text { Post-op } 3 \mathrm{~m} \\
\text { Post-op } 6 \mathrm{~m}\end{array}$ & $\begin{array}{c}8.96 \pm 2.11 \\
13.48 \pm 1.95 \\
12.52 \pm 1.95 \\
12.45 \pm 1.91\end{array}$ & $\begin{array}{c}7.37 \pm 2.28 \\
11.50 \pm 1.26 \\
10.65 \pm 12.45 \\
10.58 \pm 1.26\end{array}$ & $\begin{array}{l}.059 \\
.002 \\
.006 \\
.005\end{array}$ \\
\hline $\begin{array}{c}\text { FH } \\
\text { Pre-op } \\
\text { Post-op } 1 \mathrm{w} \\
\text { Post-op } 3 \mathrm{~m} \\
\text { Post-op } 6 \mathrm{~m} \\
\text { Cage subsidence } \\
\text { Post-op } 3 \mathrm{~m}\end{array}$ & $\begin{array}{l}15.93 \pm 2.84 \\
19.75 \pm 2.50 \\
19.23 \pm 2.47 \\
19.13 \pm 2.38 \\
2 / 28(7.1 \%)\end{array}$ & $\begin{array}{l}15.84 \pm 2.35 \\
17.85 \pm 2.36 \\
17.37 \pm 2.31 \\
17.20 \pm 2.32 \\
3 / 35(8.6 \%)\end{array}$ & $\begin{array}{l}.926 \\
.045 \\
.045 \\
.035 \\
.84\end{array}$ \\
\hline
\end{tabular}

\section{Discussion}

Lumbar spondylolisthesis is a common pathology accompanied with lumbar canal stenosis, displaying a certain degenerative imbalance and thus presentinga risk factor for degenerative scoliosis in later life. This is due to conservative treatment options being relatively inferior, thus indicating that surgical treatments offer a more meaningful approach [13]. Lumbar fusion has become an accepted treatment to treat degenerative diseases of the lumbar spine [14]. Both PLIF and TLIF are the most widely used posterior fusion techniques, which can fully expose to nerve roots. However, several literatures demonstrated that there is a risk of iatrogenic lesions of the dural sac and nerve roots as well as epidural bleeding in PLIF. For the limitations of PLIF, TLIF was introduced. TLIF is a variant of the PLIF technique described by Cloward in the 1950s [15]. It is usually performed by unilateral approach preserving the interlaminar surface on the contralateral side, which can be used as a site for additional fusion. Compared with PLIF, TLIF retains ligamentous complex, contralateral lamina and facet joints, thus maintaining spinal stability [16-17]. OLIF is a modification of the retroperitoneal approach for microsurgical anterolateral lumbar interbody fusion, which was first described by Mayer in 1997[18]. In this study, we found that the OLIF group had less intraoperative blood loss and shorter operative time, bed rest duration, and hospital stay than the TLIF group. Potentially because of the absence of back muscle injury in OLIF, we also found that the OLIF group had lower VAS scores for back pain and ODI than the TLIF group at 1 week postoperatively. In contrast to transforaminal lumbar interbody fusion, OLIF technique is performed through the retroperitoneal space and accessed by blunt dissection. Both separation of paravertebral and tissue removal of bone mass near the canal are not necessary in procedure. The separation of the paravertebral tissue and the large incision are key reasons that accounts for the high level of intraoperative blood loss and high 
incidence of postoperative incision complications. Altogether, both OLIF and PLIF display obvious differences in terms of the surgical procedure. Compared with TLIF, OLIF had the advantages of less blood loss, shorter operative time and preservation of the posterior longitudinal ligament complex, which presented as a key reason in affecting post-operative efficacy. It has been reported that no significantly improvement was found in lumbar lordosis in TLIF [19]. However, the lumbar lordosis (LL) recovered significantly in both groups in our study. We noted that the TLIF was effective in restoring normal lumbar lordosis, which is probably because that we place the interbody graft as anterior as possible to maximize the lordotic potential, and it is within the construct in combination with compression from the posterior column. Other studies show that the effect of TLIF in restoring normal lumbar lordosis depends on compression of posterior structure of the lumbar vertebrae [20]. Several literatures demonstrated that LL is restored well in lateral lumbar interbody fusion. Thus far, we expect that OLIF will do better in deformity correction. Luckily, differences were found in LL in two groups after surgery. In OLIF group, the mean improved Cobb angle is larger than that of TLIF, demonstrating that the correction in lumbar lordosis is better in OLIF. Kepller et al. demonstrated that more lumbar lordosis was associated with more back and leg pain as assessed by VAS [21]. Fujibayashi demonstrated that clinical results are related more to the effect of deformity correction than to indirect neural decompression [13]. This may be explained that why the VAS scores is less in OLIF group after the surgery. In addition, restoration of $\mathrm{DH}$ in the fusion segment significantly improved the compression of nerve canal by reduction of disc bulging and elongation of the hypertrophied ligamentum flavum. Both surgical procedures increase DH of the diseased segment. Moreover, the OLIF group showed higher restoration of DH and FH than TLIF group postoperatively. This is reasonable, because we inserted a relatively larger cage into the target disc in OLIF. The height and width of OLIF cage are $8-14 \mathrm{~mm}$ and $55 \mathrm{~mm}$ respectively while the cage in TLIF is $8-12 \mathrm{~mm}$ in height and $30 \mathrm{~mm}$ in width [23]. The height of intervertebral can be increased by using larger and wider cage, the same as intervertebral foramen height and vertebral canal area. The wide cage allows it to rest on the hard epiphyseal ring around the vertebral body, rather than on the relatively weak area of the cortical bone in the central depression of the endplate.

For patients in TLIF group with a combination of supplemental fixation at a given level, there was $8.6 \%$ (3 of 35) rate of cage subsidence. Of the 3 patients with radiographical subsidence, only 1 was symptomatic. Besides, for patients in OLIF group with a combination of unilateral fixation, there was $7.1 \%$ (2 of 28) of cage sedimentation. It may prove that the effect on avoiding subsidence in unilateral fixation is good enough. Besides, as mentioned by Tien $\mathrm{V}$, the inferior endplate is $40 \%$ stronger than the superior endplate [24]. In 5 cases of our study, the cage was inserted superior endplate, which did consistent the theory mentioned above. In the current reports, the complication rates of TLIF were range from 7.1 to $21.6 \%$ [25-29] including rod-broken and cage migration. The complication incidences of OLIF were varied in literatures, ranging from $3.7 \%$ to $58.3 \%$ [13-31]. Ohtori et al. demonstrated that segmental artery injury occurred in 1 patient and the surgery was converted to open surgery. Zeng et al. reported that the complication incidence of OLIF was $13.62 \%$, such as cerebral infraction and reoperation, both of which were only one case. Except for several serious complications mentioned above, the rest are all transient symptoms. In this study, two patients who underwent OLIF showed ileus on the first postoperative day. The postoperative ileus improved spontaneously in the next several days. One patient experienced thigh and numbness postoperatively in the OLIF group, which alleviated within 7 days after surgery. There was no ureteral injury or lesion to sympathetic chain. In the TLIF group, CSF leakage due to thecal sac injury and root injury was confirmed in three cases. The drainage tube was removed 7 days after the operation. Superficial incision infection occurred in 3 patients in the TLIF group, which was treated with dressing change and antibiotics. However, several disadvantages can't be ignored in OLIF technique. In the process of disc removal, repeated fluoroscopy is needed and patients are exposed to more radiation than TLIF. Besides, the larger cage may lead to iatrogenic injury to nerve root, especially to the upper nerve root of the oblique side of the kambin triangle. What's more, the cage is more expensive than traditional one and some patients in poor family can't afford it.

\section{Limitations}

A limitation of the study was that it was a retrospective study with a relatively small sample size. Moreover, the inclusion criteria were rather restrictive and may have contributed to a selection bias that may have led to an underestimation of incidence rates for nonunion, subsidence, and surgical approach-related complications. The intention is to follow up this study in the future to obtain further information aimed at improving the deficiencies identified in this article. In addition, increase the number of followup cases in an attempt to reduce the error of follow-up data to further improve the accuracy of this study.

\section{Conclusion}

Both OLIF and TLIF can achieve satisfactory clinical results in the treatment of lumbar spondylolisthesis accompanied with lumbar stenosis. However, compared with TLIF, a smaller incision, shorter ansthesia time, less blood loss and earlier postoperative activities in OLIF did exhibit a greater advantage, attracting more and more attention in surgeons.

\section{Conflict of Interest}

The authors declare that they have no conflict of interest.

\section{Funding}

There were no external funding sources for this study.

\section{Acknowledgment}

Thanks to all patients involved in this study from the first affiliated hospital of Soochow University. 


\section{References}

1. De Kunder SL, Van Kuijk SMJ, Rijkers K, Caelers IJMH, Van Hemert WLW, et al. (2017) Transforaminal lumbar interbody fusion (TLIF) versus posterior lumbar interbody fusion (PLIF) in lumbar spondylolisthesis: a systematic review and meta-analysis. Spine J 17: 17121721.

2. Eck JC, Sharan A, Ghogawala Z, Resnick DK, Watters WC, et al. (2014) Guideline update for the performance of fusionprocedures for degenerative disease of the lumbar spine Part 7: lumbar fusion for intractable low-back pain without stenosis or spondylolisthesis[J]. Journal of neurosurgery Spine 21: 42-47.

3. Harms JG, Jeszenszky D (1998) Die posteriore, lumbale, interkorporelle Fusion in unilateraler transforaminaler Technik. Oper Orthop Traumatol 10: $90-102$

4. Cloward RB (1953) The treatment of ruptured lumbar intervertebral discs by vertebral body fusion. I.Indications, operative technique, after care. J Neurosurg 10(2): 154-168.

5. Harms J, Rolinger H (1981) A one-stager procedure in operative treatment of spondylolistheses: dorsal traction-reposition and anterior fusion. Z Orthop Ihre Grenzgeb 120(3): 343-347.

6. Kawaguchi Y, Yabuki S, Styf J, Olmarker K, Rydevik B, et al. (1996) Back muscle injury after posterior lumbar spine surgery. Topographic evaluation of intramuscular pressure and blood flow in the porcine back muscle during surgery. Spine (Phila Pa 1976) 21(22): 2683-2688.

7. Potter BK, Freedman BA, Verwiebe EG, Hall JM, Polly DW Jr, et al. (2005) Transforaminal lumbar interbody fusion: clinical and radiographic results and complications in 100 consecutive patients. J Spinal Disord Tech 18(4): 337-346.

8. Silvestre C, Mac Thiong JM, Hilmi R, et al. (2012) Complications and Morbidities of Mini-open Anterior Retroperitoneal Lumbar Interbody Fusion, Oblique Lumbar Interbody Fusion in 179 Patients. Asian Spine J, 6(2): 89-97.

9. Mayer HM (1997) A new microsurgical technique for minimally invasive anterior lumbar interbody fusion[J]. Spine (Phila Pa 1976) 61(6): 691699.

10. Li JX, Phan K (2017) Oblique Lumbar Interbody Fusion: Technical Aspects, Operative Outcomes, and Complications. World Neurosurg 98: 113-123.

11. Xu DS,Walker CT, Godzik J, Turner JD, Smith W, et al. (2018) Minimally invasive anterior, lateral, and oblique lumbar interbody fusion: a literature review. Ann Transl Med 6(6): 104.

12. Hah R (2019) Lateral and Oblique Lumbar Interbody Fusion-Current Concepts and a Review of Recent Literature. Curr Rev Musculoskelet Med 22: 305-310.

13. Fujibayashi S, Hynes RA, Otsuki B, Kimura H, Takemoto $M$, et al (2015) Effect of indirect neural decompression through oblique lateral interbody fusion for degenerative lumbar disease. Spine 40(3): E175-82.

14. Umeta RS (2011) Techniques of lumbar-sacral spine fusion in spondylosis: systematic literature Review and meta-analysis of randomized clinical trials. Spine J 11(7): 668-676.

15. Humphreys SC, Hodges SD, Patwardhan AG, Eck JC, Murphy RB, et al. (2001) Comparison of posterior and transforaminal approaches to lumbar interbody fusion. Spine (Phila Pa 1976) 26(5): 567-571.

16. Audat Z, Moutasem O, Yousef K (2012) Comparison of clinical and radiological results of posterolateral fusion, posterior lumbar interbody fusion and transforaminal lumbar interbody fusion techniques in the treatment of degenerative lumbar spine. Singapore Med J 53(3): 183187.

17. Chen YL, Zhu ZH, Wang YK, Fan SW, Fang XQ, et al. (2018) Effects of oblique lateral interbody fusion and transforaminal lumbar interbody fusion for lordosis correction in degenerative lumbar diseases. (Ed.), Zhonghua Yi Xue Za Zhi 98: 1990-1995.

18. Recnik G, Kosak R (2013) Influencing segmental balance in isthmic spondylolithesis using transforaminal lumbar interbody fusion. J Spinal Disord Tech 26(5): 246-251.

19. Jagannathan J, Sansur CA,Oskouian RJ, et al. (2009) Radiographic restoration of lumbar alignment after transforaminal lumbar interbody fusion. Neurosurgery 64(5): 955-963.

20. Kepler CK, Rihn JA, Radcliff KE, Amar A Patel MD, D Greg Anderson MD, et al. (2012) Restoration of lordosis and disk height after single-level transforaminal lumbar interbody fusion. Orthop Surg 4: 15-20.

21. Gragnaniello C, Seex K (2016) Anterior to psoas (ATP) fusion of the lumbar spine: evolution of a technique facilitated by changes in equipment. J Spine Surg 2(4): 256-265.

22. Le TV, Baaj AA, Dakwar E, Burkett CJ, Murray G, et al. (2012) Subsidence of polyetheretherketone intervertebral cages in minimally invasive lateral retroperitoneal transpsoas lumbar interbody fusion.Spine (Phila Pa 1976) 37(14): 1268-1273.

23. Suk KS, Lee HM, Kim NH, Ha JW (2000) Unilateral versus bilateral pedicle screw fixation in lumbar spinal fusion. Spine 25(14): 1843-1847.

24. Xue HM, Tu YH, Cai MW (2012) Comparison of unilateral versus bilateral instrumented transforaminal lumbar interbody fusion in degenerative lumbar diseases. Spine J 12(3): 209-215.

25.Xie YZ, Ma H, Li H, Ding W, Zhao CQ (2012) Comparative study of unilateral and bilateral pedicle screw fixation in posterior lumbar interbody fusion. Orthopedics 35(10): E1517-E1523.

26. Choi UY, Park JY, Kim KH, Kuh SU, Chin DK, et al. (2013) Unilateral versus bilateral percutaneous pedicle screw fixation in minimally invasive transforaminal lumbar interbody fusion. Neurosurg Focus 35(2): E11.

27. Liang Y, Shi WB, Jiang C, Chen Z, Liu F, et al. (2015) Clinical outcomes and sagittal alignment of single-level unilateral instrumented transforaminal lumbar interbody fusion with a 4 to 5-year follow-up. Eur spine J 24(11): 2560-2566.

28. Molloy S, Butler JS, Benton A et al. (2016) A new extensile anterolateral retroperitoneal approach for lumbar interbody fusion from L1 to S1: a prospective series with clinical outcomes [J]. Spine J 16(6): 786-791.

29. Sato J, Ohtori S, Orita S, Yamauchi K, Eguchi Y, et al. (2017) Radiographic evaluation of indirect decompression of mini-open anterior retroperitoneal lumbar interbody fusion: oblique lateral interbody fusion for degenerated lumbar spondylolisthesis. Eur Spine J 26(3): 671-678.

30. Ohtori S, Mannoji C, Orita S, Eguchi Y, Ochiai N, et al. (2015) Mini-Open Anterior Retroperitoneal Lumbar Interbody Fusion: Oblique Lateral Interbody Fusion for Degenerated Lumbar Spinal Kyphoscoliosis. Asian Spine J 9(4): 565-572.

31. Mehren C, Mayer HM, Zandanell C, Siepe CJ, Korge A (2016) The oblique anterolateral approach to the lumbar spine provides access to the lumbar spine with few early complications. Clin Orthop Relat Res 474(9): 2020-2027. 
CC (P) This work is licensed under Creative Commons Attribution 4.0 License

To Submit Your Article Click Here:

Submit Article

DOI: $10.32474 /$ OSMOAJ.2020.03.000173

$\begin{gathered}\text { Orthopedics and Sports Medicine } \\ \text { Open Access Journal }\end{gathered}$
Assets of Publishing with us
- Global archiving of articles
- Immediate, unrestricted online access
- Rigorous Peer Review Process
- Authors Retain Copyrights

